\title{
Referral criteria for outpatient specialty palliative cancer care : an international consensus
}

\section{Hui, David}

2016-12

Hui , D , Mori , M , Watanabe , S M , Caraceni , A , Strasser , F , Saarto , T , Cherny , N , Glare , P , Kaasa , S \& Bruera , E 2016, ' Referral criteria for outpatient specialty palliative cancer care : an international consensus ' , Lancet Oncology , vol. 17 , no. 12 , pp.

E552-E559 . https://doi.org/10.1016/S1470-2045(16)30577-0

http://hdl.handle.net/10138/230307

https://doi.org/10.1016/S1470-2045(16)30577-0

publishedVersion

Downloaded from Helda, University of Helsinki institutional repository.

This is an electronic reprint of the original article.

This reprint may differ from the original in pagination and typographic detail.

Please cite the original version. 


\section{Referral criteria for outpatient specialty palliative cancer care: an international consensus}

David Hui, Masanori Mori, Sharon M Watanabe, Augusto Caraceni, Florian Strasser, Tiina Saarto, Nathan Cherny, Paul Glare, Stein Kaasa, Eduardo Bruera

Although outpatient specialty palliative-care clinics improve outcomes, there is no consensus on who should be referred or the optimal timing for referral. In response to this issue, we did a Delphi study to develop consensus on a list of criteria for referral of patients with advanced cancer at secondary or tertiary care hospitals to outpatient palliative care. 60 international experts (26 from North America, 19 from Asia and Australia, and 11 from Europe) on palliative cancer care rated 39 needs-based criteria and 22 time-based criteria in three iterative rounds. Nearly all experts responded in each round. Consensus was defined by an a-priori agreement of $70 \%$ or more. Panellists reached consensus on 11 major criteria for referral: severe physical symptoms, severe emotional symptoms, request for hastened death, spiritual or existential crisis, assistance with decision making or care planning, patient request for referral, delirium, spinal cord compression, brain or leptomeningeal metastases, within 3 months of advanced cancer diagnosis for patients with median survival of 1 year or less, and progressive disease despite second-line therapy. Consensus was also reached on 36 minor criteria for specialist palliative-care referral. These criteria, if validated, could provide guidance for identification of patients suitable for outpatient specialty palliative care.

\section{Introduction}

A growing body of evidence ${ }^{1-5}$ from the past decade suggests that early involvement of specialty palliative care, concurrent with routine oncological care, is associated with improved quality of life, symptom burden, patient and caregiver satisfaction, and possibly survival. Oncologists deliver high-quality primary palliative care on the front lines. ${ }^{6,7}$ However, some patients have more complex supportive care needs and would benefit from referral to a palliative-care specialist. Outpatient clinics are crucial for early palliative access for patients with cancer in the ambulatory setting while they are still undergoing treatment, ${ }^{8-11}$ and are a major indicator of integration. ${ }^{12}$ A 2014 study $^{5}$ showed that, compared with inpatient palliative-care consultation, referral to outpatient palliative care is associated with significant improvement in end-of-life outcomes.

Several organisations, such as the European Society for Medical Oncology (ESMO), the American Society of Clinical Oncology, WHO, and the National Comprehensive Cancer Network (NCCN), along with many opinion leaders, have called for timely specialty palliative-care referral and for more resources to support palliative-care programmes. ${ }^{13-15}$ However, a 2016 systematic review ${ }^{16}$ showed heterogeneity in terms of who should be referred and when referral should occur. This lack of consensus partly contributes to inconsistent and delayed referrals. To optimise the use of scarce palliative-care resources, patients need to be referred at the right time for the right reasons. Therefore, consensus on simple, robust, and valid referral criteria is urgently needed.

A consensus set of referral criteria would allow referring clinicians to identify appropriate patients for palliative-care interventions, administrators to benchmark their programmes, researchers to standardise trial inclusion criteria, and policy makers to develop clinical care pathways and allocate appropriate resources. As part of the Delphi study, we aimed to reach an international consensus among experts on referral criteria to outpatient palliative care for patients with advanced cancer who are being treated at secondary or tertiary care hospitals with an interdisciplinary palliativecare team in place (assuming that service delivery is not an issue).

\section{Methods}

\section{Participant selection}

This study was approved by the institutional review board at MD Anderson Cancer Center (Houston, TX, USA), which waived the need for informed consent. Our Delphi panel consisted of international experts who have an in-depth understanding of outpatient palliative cancer care through their training, clinical practice, or research. We included only individuals who met all four of the following eligibility criteria: a physician with an active (at least $20 \%$ clinical) specialty clinical practice in either palliative care or oncology, or both, with at least 5 years of post-qualification clinical experience; working at a center with outpatient palliative-care access; at least one of board certification or equivalent in both oncology and palliative care, have published in the area of integration of palliative care and oncology in the past 10 years, or have been involved in national or international palliative-care guideline development on the topic of integration; and able to communicate in written English.

We searched for potentially eligible candidates on the basis of a literature review of outpatient palliative care; membership of the Multinational Association of Supportive Care in Cancer (MASCC) Palliative Care Study Group, the NCCN Palliative Care Guideline Committee, or the ESMO Palliative Care Working Group; and nominations by the steering committee. We emailed potentially eligible candidates an invitation outlining the
Lancet Oncol 2016; 16: e552-59 Department of Palliative Care, Rehabilitation and Integrative Medicine, University of Texas MD Anderson Cancer Center Houston, TX, USA (D Hui MD Prof E Bruera MD); Palliative Care Team, Seirei Mikatahara General Hospital, Hamamatsu, Shizuoka, Japan (M Mori MD); Division of Palliative Care Medicine, Department of Oncology, University of Alberta, Edmonton, AB, Canada (Prof S M Watanabe MD); Palliative Care, Pain Therapy and Rehabilitation, Fondazione IRCCS Istituto Nazionale dei Tumori di Milano, Milan, Italy (Prof A Caraceni MD); Oncological Palliative Medicine, Hematology-Oncology, Cantonal Hospital, St Gallen, Switzerland (F Strasser MD); Department of Palliative Care, Helsinki University Central Hospital, Cancer Center, Helsinki, Finland (ProfT Saarto MD); Cancer Pain and Palliative Medicine Service, Department of Medical Oncology, Shaare Zedek Medical Center, Jerusalem, Israel (N Cherny MD); Pain and Palliative Care Service, Department of Medicine, Memorial Sloan Kettering Cancer Center, New York, NY, USA (Prof P Glare MD); and European Palliative Care Research Centre, Department of Cancer Research and Molecular Medicine, Norwegian University of Science and Technology, Trondheim, and Department of Oncology, Oslo University Hospital and University of Oslo, Oslo, Norway (Prof S Kaasa MD)

Correspondence to: Dr David Hui, Department of Palliative Care, Rehabilitation and Integrative Medicine Unit 1414, University of Texas MD Anderson Cancer Center, Houston, TX 77030, USA dhui@mdanderson.org 
eligibility criteria and the study process. To maximise inclusion, we also asked potential individuals to send us the names of other potential candidates, whom we subsequently contacted (the criteria outlined previously were applied to these recommendations). All individuals who responded, confirmed that they met the eligibility criteria, and expressed a willingness to participate were included in the study.

\section{Eligibility criteria}

Because referral criteria vary substantially by cancer stage, clinical setting, and local resource availability, we specifically focused on referral criteria for patients with advanced cancer being treated at secondary or tertiary care hospitals with an interdisciplinary palliative-care team in place, assuming that service delivery is not an issue. The list of potential criteria was generated on the basis of a systematic review ${ }^{16}$ by our group, in which we identified 20 unique categories of criteria. Six of these categories were commonly cited for referraltwo time-based criteria (ie, cancer trajectory and prognosis) and four needs-based criteria (ie, physical symptoms, performance status, end-of-life care planning, and psychosocial distress). Before each Delphi round, steering committee members reviewed and revised the list of referral criteria and specific wording used.

\section{Process}

Between Sept 28, 2015, and Feb 16, 2016, we used the Qualtrics Survey Software (Qualtrics, Provo, UT, USA) to administer web-based surveys to our participants. Our Delphi study consisted of three rounds, each lasting 4 weeks and spaced 2-6 weeks apart (figure 1). Non-respondents were sent weekly email reminders. We did not provide any financial incentives.

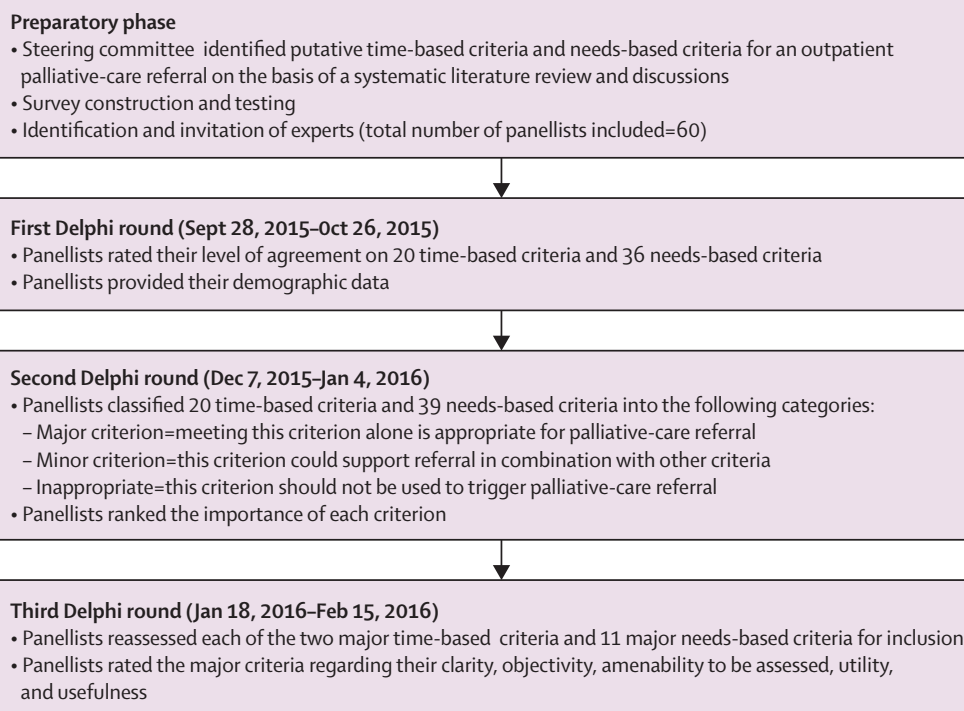

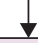

Third Delphi round (Jan 18, 2016-Feb 15, 2016)

- Panellists reassessed each of the two major time-based criteria and 11 major needs-based criteria for inclusion

- Panellists rated the major criteria regarding their clarity, objectivity, amenability to be assessed, utility,

and usefulness

Figure 1: Delphi process to reach consensus for outpatient palliative-care referral criteria
The first Delphi round included 20 time-based criteria and 36 needs-based criteria. For each time-based criterion, we asked panellists to independently state the appropriateness of timing on a five-point Likert scale ("much too early", "too early", "appropriate", "too late", and "much too late"). Answers that were marked as "appropriate" were considered for consensus determination. For each needs-based criterion, we also used a five-point Likert scale ("strongly agree", "agree", "neither agree nor disagree", "disagree”, and "strongly disagree"). "Strongly agree" and "agree" were combined and coded as an overall agreement in our analysis. A consensus was defined a priori as a minimum of $70 \%$. We also collected basic demographic information from the experts, such as age group, type of clinical practice, and years of experience (appendix).

The second Delphi round included 20 putative time-based criteria and 39 putative needs-based criteria, with three new needs-based indicators added (unrealistic hope or denial, participation in phase 2 or 3 clinical trials, patient expected to have aggressive disease course at the time of diagnosis [eg, survival $<6$ months]) on the basis of participants' comments after the first round. During the first round, some panellists commented on the need to identify not only which criteria were appropriate but also their relative importance. For each indicator in the second round, participants were provided with the mean percentage of agreement from the previous round (among those who participated), and asked if each item was appropriate as a referral criterion. If experts answered "yes", they were then asked whether the item should be a major (ie, its presence in isolation is sufficient to trigger referral) or minor (ie, other similar-level criteria would be needed to trigger referral) criterion. Furthermore, they were asked to rate the relative importance of each criterion from 0 (least important) to 10 (most important).

The third Delphi round focused on a shortlist of criteria with $70 \%$ or higher agreement for being a major criterion in the second round. Experts were asked to express their level of agreement (from "strongly agree" to "strongly disagree"). Any criterion that was marked as "appropriate" and reached consensus in the second round and was not included as a major criterion was classified as a minor criterion. The experts were then asked to rate the major criteria on a numeric scale from 0 ("not at all") to 10 ("very much") in regard to whether they were clearly stated, objective, amenable to accurate assessment, amenable to being used for routine screening in the oncology practice, useful to facilitate outpatient palliative-care referral in their own countries, and useful to facilitate outpatient palliative-care referral at their own institutions.

We used the McNemar exact test to determine the stability of responses between the second and third Delphi rounds. We did our statistical analyses with Stata (version 12.1). 


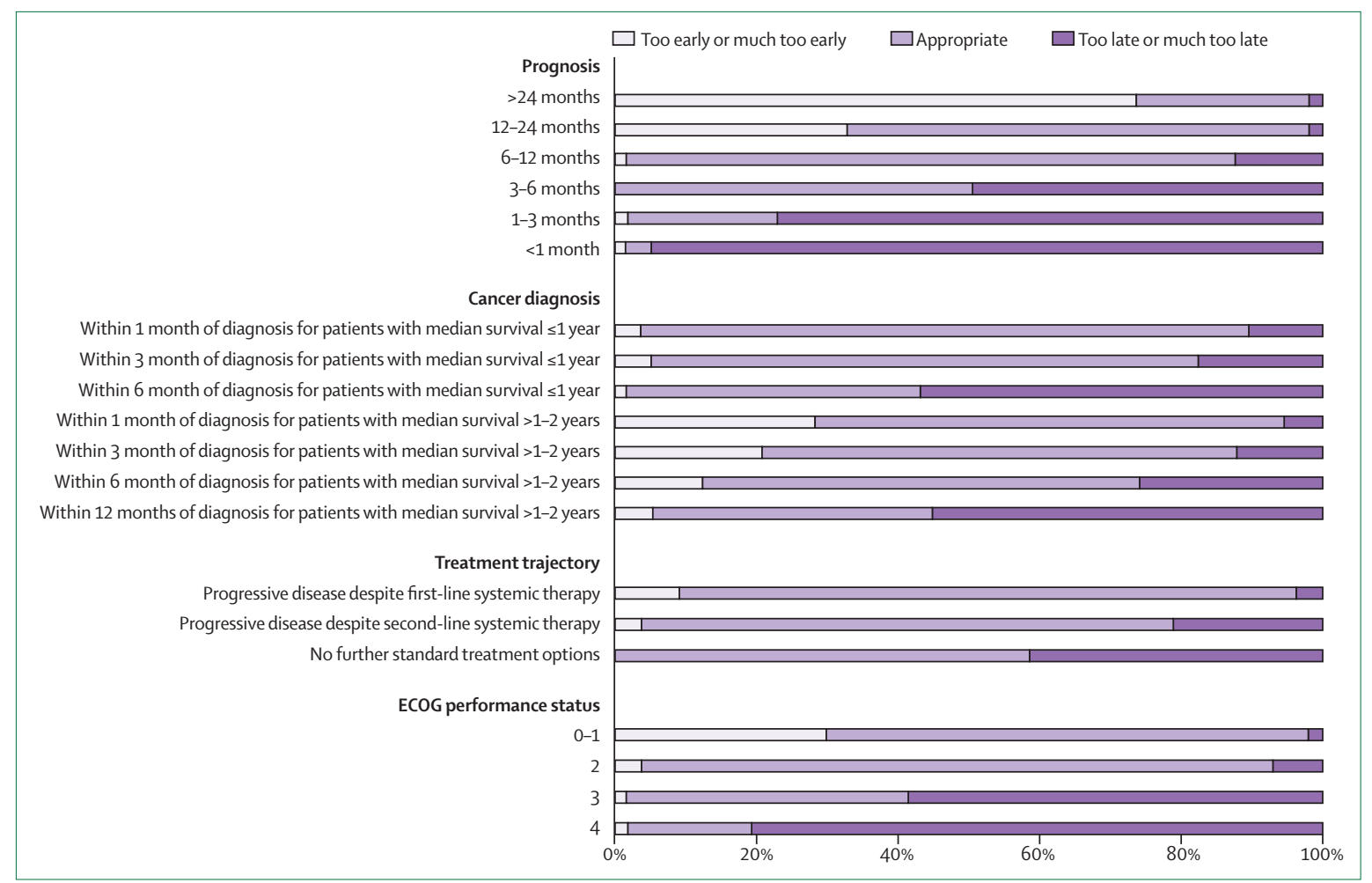

Figure 2: Most appropriate timing to refer a patient with advanced cancer to outpatient palliative care

We asked panellists to independently state the appropriateness of timing of referral with a five-point Likert scale ("much too early", "too early", "appropriate", "too late", or "much too late") in the first Delphi round. A consensus was defined as a minimum of 70\% of experts rating timing as "appropriate". ECOG=Eastern Cooperative Oncology Group.

\section{Findings}

60 experts fulfilled our eligibility criteria and agreed to be part of the panel. 59 (98\%) responded in the first round, $56(93 \%)$ in the second, and 58 (97\%) in the third. Most of the panellists were male $(n=38[63 \%])$ and dually trained in palliative care and oncology $(n=32[54 \%])$. They reported a median of 10 years' experience (IQR $7 \cdot 0-18 \cdot 5)$ in palliative care and 12 years' experience (8-20) in oncology practice (appendix).

In the first Delphi round, more than $70 \%$ of panellists marked 22 (61\%) of 36 needs-based criteria and six (30\%) of 20 time-based criteria as "appropriate" to trigger outpatient palliative-care referral (figure 2, table 1). In the second Delphi round, panellists classified nine $(23 \%)$ of the needs-based criteria and two $(10 \%)$ of the time-based criteria as major, 23 (59\%) of the needs-based criteria and $13(65 \%)$ of the time-based criteria as minor criteria, and seven $(18 \%)$ of the need-based criteria and five $(25 \%)$ of the time-based criteria as inappropriate (table 1).

In the third Delphi round, panellists were asked to provide their final decision about the appropriateness of each of the 11 major criteria identified during the second round as triggers for outpatient palliative-care referral. All 11 items achieved greater than 70\% agreement as major criteria in both the second and third rounds (table 2). Responses to criteria remained stable between the second and third rounds, except for the criterion concerning spiritual or existential crisis, for which the level of agreement significantly increased (71\% vs $91 \%$; $\mathrm{p}=0 \cdot 007$ ).

The highest levels of agreement were for patient distress, including severe physical symptoms (100\% agreement), severe emotional symptoms ( $97 \%$ agreement), request for hastened death ( $96 \%$ agreement), and spiritual or existential crisis ( $91 \%$ agreement; table 2). The two time-based criteria-within 3 months of diagnosis for patients with median survival of 1 year or less and progressive disease despite second-line systemic therapyboth had $88 \%$ agreement (table 2).

On the numeric rating scale, the median scores for the major criteria were 9 (IQR 8-10) for "clearly stated", 8 for "objective in nature" (7-9), and 8 for "could be assessed accurately" (7-9). Panellists' scores also suggested that the major criteria could be used for routine screening in oncology practice (median 8 [IQR 7-9]), and were useful to facilitate outpatient palliative-care referral at their own institution (8 [7-9]) and in their own country (8 [7-9]).

\section{Discussion}

In this Delphi survey, international experts identified 11 major criteria and 36 minor criteria to trigger palliative- 


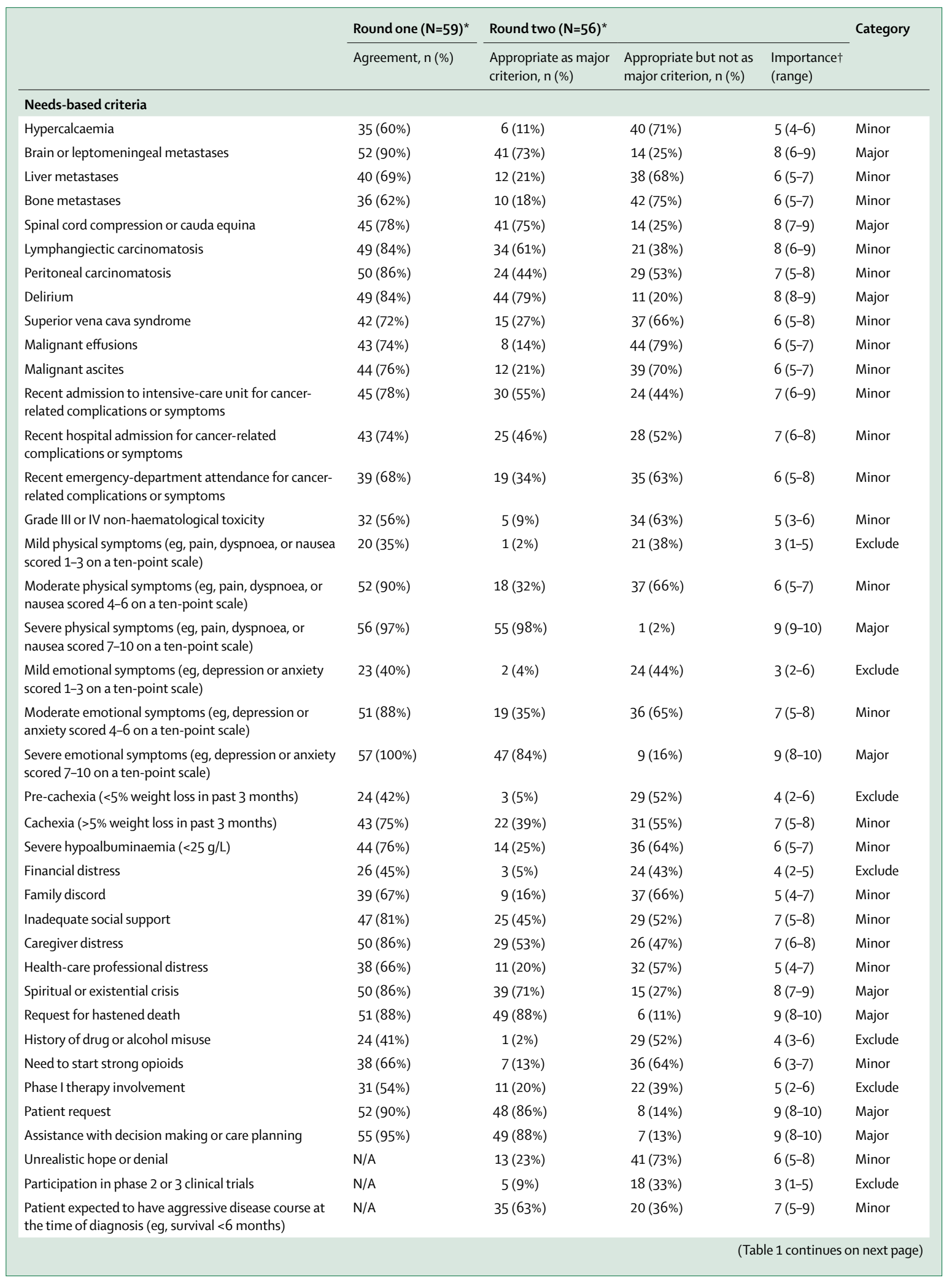




\begin{tabular}{|c|c|c|c|c|c|}
\hline & \multirow{2}{*}{$\begin{array}{l}\text { Round one }(\mathrm{N}=59)^{*} \\
\text { Agreement, } \mathrm{n}(\%)\end{array}$} & \multicolumn{3}{|l|}{ Round two $(\mathrm{N}=56)^{*}$} & \multirow[t]{2}{*}{ Category } \\
\hline & & $\begin{array}{l}\text { Appropriate as major } \\
\text { criterion, } \mathrm{n}(\%)\end{array}$ & $\begin{array}{l}\text { Appropriate but not as } \\
\text { major criterion, } \mathrm{n}(\%)\end{array}$ & $\begin{array}{l}\text { Importance } \dagger \\
\text { (range) }\end{array}$ & \\
\hline \multicolumn{6}{|l|}{ (Continued from previous page) } \\
\hline \multicolumn{6}{|l|}{ Time-based criteria } \\
\hline Physician-estimated life expectancy > 24 months & $14(25 \%)$ & $0(0 \%)$ & $28(50 \%)$ & $3(1-5)$ & Exclude \\
\hline Physician-estimated life expectancy $12-24$ months & $38(66 \%)$ & $6(11 \%)$ & $43(77 \%)$ & $5(3-7)$ & Minor \\
\hline Physician-estimated life expectancy 6-12 months & $50(86 \%)$ & $35(63 \%)$ & $18(32 \%)$ & $8(6-9)$ & Minor \\
\hline Physician-estimated life expectancy 3-6 months & $29(51 \%)$ & $36(64 \%)$ & $18(32 \%)$ & $9(7-10)$ & Minor \\
\hline Physician-estimated life expectancy $1-3$ months & $12(21 \%)$ & $27(48 \%)$ & $12(21 \%)$ & $8(5-10)$ & Minor \\
\hline Physician estimated life expectancy $<1$ month & $2(3 \%)$ & $17(30 \%)$ & $9(16 \%)$ & $8(3-10)$ & Exclude \\
\hline $\begin{array}{l}\text { Within } 1 \text { month of diagnosis of advanced or incurable } \\
\text { cancer with median survival of } 1 \text { year or less }\end{array}$ & $50(86 \%)$ & $36(65 \%)$ & $17(31 \%)$ & $8(7-9)$ & Minor \\
\hline $\begin{array}{l}\text { Within } 3 \text { months of diagnosis of advanced or incurable } \\
\text { cancer with median survival of } 1 \text { year or less }\end{array}$ & $45(78 \%)$ & $40(71 \%)$ & $14(25 \%)$ & $8(7-9)$ & Major \\
\hline $\begin{array}{l}\text { Within } 6 \text { months of diagnosis of advanced or incurable } \\
\text { cancer with median survival of } 1 \text { year or less }\end{array}$ & $24(41 \%)$ & $18(32 \%)$ & $22(39 \%)$ & $6(5-8)$ & Minor \\
\hline $\begin{array}{l}\text { Within } 1 \text { month of diagnosis of advanced or incurable } \\
\text { cancer with median survival of 1-2 years }\end{array}$ & $38(67 \%)$ & $8(14 \%)$ & $36(64 \%)$ & $5(4-7)$ & Minor \\
\hline $\begin{array}{l}\text { Within } 3 \text { months of diagnosis of advanced or incurable } \\
\text { cancer with median survival of } 1-2 \text { years }\end{array}$ & $39(67 \%)$ & $11(20 \%)$ & $38(68 \%)$ & $6(4-7)$ & Minor \\
\hline $\begin{array}{l}\text { Within } 6 \text { months of diagnosis of advanced or incurable } \\
\text { cancer with median survival of } 1-2 \text { years }\end{array}$ & $36(62 \%)$ & $18(32 \%)$ & $33(59 \%)$ & $5(4-8)$ & Minor \\
\hline $\begin{array}{l}\text { Within } 12 \text { months of diagnosis of advanced or incurable } \\
\text { cancer for patients with median survival of } 1-2 \text { years }\end{array}$ & $23(40 \%)$ & $7(13 \%)$ & $31(56 \%)$ & $5(4-7)$ & Exclude \\
\hline $\begin{array}{l}\text { Diagnosis of advanced cancer with progressive disease } \\
\text { despite first-line systemic therapy (incurable) }\end{array}$ & $50(88 \%)$ & $35(63 \%)$ & $19(34 \%)$ & $8(6-9)$ & Minor \\
\hline $\begin{array}{l}\text { Diagnosis of advanced cancer with progressive disease } \\
\text { despite second-line systemic therapy (incurable) }\end{array}$ & $43(75 \%)$ & $39(70 \%)$ & $15(27 \%)$ & $8(7-9)$ & Major \\
\hline $\begin{array}{l}\text { Diagnosis of advanced cancer with no further standard } \\
\text { palliative cancer treatment options (incurable) }\end{array}$ & $34(59 \%)$ & $32(57 \%)$ & $17(30 \%)$ & $8(6-9)$ & Minor \\
\hline ECOG performance status 0-1 & $39(68 \%)$ & $6(11 \%)$ & $29(52 \%)$ & $5(2-6)$ & Exclude \\
\hline ECOG performance status 2 & $51(89 \%)$ & $18(32 \%)$ & $33(59 \%)$ & $6(5-8)$ & Minor \\
\hline ECOG performance status 3 & $23(40 \%)$ & $25(45 \%)$ & $20(36 \%)$ & $7(5-9)$ & Minor \\
\hline ECOG performance status 4 & $10(17 \%)$ & $19(34 \%)$ & $8(14 \%)$ & $8(3-9)$ & Exclude \\
\hline $\begin{array}{l}\text { During the second round, the panellists were asked to classify e } \\
\text { not reach consensus as a major criterion, but had } 70 \% \text { or great } \\
\text { Group. *Because not all respondents answered all questions, in } \\
\text { importance on a numeric scale ranging from } 0 \text { ("not at all") to }\end{array}$ & $\begin{array}{l}\text { ach criterion as a major c } \\
\text { er of the respondents agr } \\
\text { some instances the denc } \\
10 \text { ("very much"). }\end{array}$ & $\begin{array}{l}\text { ing in the first round. } \\
\text { inator used to calcula }\end{array}$ & $\begin{array}{l}\text { A=not applicable. } \mathrm{ECOG} \\
\text { he percentages was diff }\end{array}$ & Ern Cooper & $\begin{array}{l}\text { is minor if it c } \\
\text { e Oncology } \\
\text { ored }\end{array}$ \\
\hline
\end{tabular}

care referral. The presence of any major criterion alone could be sufficient to trigger an outpatient palliative-care referral. With further validation, these criteria could be useful as triggers to initiate referral of patients with cancer to a specialist outpatient palliative-care clinic.

Outpatient palliative-care clinics are becoming increasingly common in cancer centres, and are imperative to facilitate timely referrals. ${ }^{8,17}$ Although several researchers have proposed referral criteria for inpatient palliative care, ${ }^{18}$ consensus on outpatient referral criteria has been limited. ${ }^{16}$ We were surprised by the large number of criteria that reached consensus in this study, despite the diverse professional and cultural backgrounds of the 60 panellists. This finding suggests that some universal patient phenotypes could be appropriate for outpatient palliative care, irrespective of health-care system or boundaries. The high response rate in all three rounds was reassuring, and implies that the issue is topical and of high relevance to clinical practice.

Four of the major needs-based criteria were related to severe distress, which makes sense-palliative care was developed as a discipline to help to alleviate suffering, and specialists have acquired substantial expertise in symptom management. ${ }^{19,20}$ Several studies ${ }^{1-4}$ have shown that outpatient palliative-care referral is associated with improvement in symptom control and quality of life. In view of the increasing emphasis on primary palliative care delivered by oncologists, our panellists suggested that patients with any severe symptom should be referred, although having one moderate symptom alone might not be adequate for referral. Although 


\begin{tabular}{|c|c|c|c|c|}
\hline & Category & $\begin{array}{l}\text { Second-round } \\
\text { agreement, } \\
\mathrm{n}(\%)\end{array}$ & $\begin{array}{l}\text { Third-round } \\
\text { agreement, } \\
\mathrm{n}(\%)\end{array}$ & $\mathbf{p}^{*}$ \\
\hline \multicolumn{5}{|l|}{ Needs-based criteria } \\
\hline $\begin{array}{l}\text { Severe physical symptoms (eg, pain, dyspnoea } \\
\text { or nausea scored 7-10 on a ten-point scale) }\end{array}$ & Distress & $55(98 \%)$ & $58(100 \%)$ & $>0.99$ \\
\hline $\begin{array}{l}\text { Severe emotional symptoms (eg, depression or } \\
\text { anxiety scored } 7-10 \text { on a ten-point scale) }\end{array}$ & Distress & $47(84 \%)$ & $56(97 \%)$ & 0.07 \\
\hline Request for hastened death & Distress & $49(88 \%)$ & $55(96 \%)$ & 0.13 \\
\hline Spiritual or existential crisis & Distress & $39(71 \%)$ & $53(91 \%)$ & 0.007 \\
\hline $\begin{array}{l}\text { Assistance with decision making or care } \\
\text { planning }\end{array}$ & Other & $49(88 \%)$ & $55(95 \%)$ & 0.45 \\
\hline Patient request & Other & $48(86 \%)$ & $55(95 \%)$ & 0.34 \\
\hline Delirium & Neurological & $44(79 \%)$ & $51(88 \%)$ & 0.42 \\
\hline Brain or leptomeningeal metastases & Neurological & $41(73 \%)$ & $43(74 \%)$ & $>0.99$ \\
\hline Spinal cord compression or cauda equina & Neurological & $41(75 \%)$ & $42(72 \%)$ & 0.85 \\
\hline \multicolumn{5}{|l|}{ Time-based criteria } \\
\hline $\begin{array}{l}\text { Within } 3 \text { months of diagnosis of advanced or } \\
\text { incurable cancer for patients with median } \\
\text { survival of } 1 \text { year or less }\end{array}$ & $\begin{array}{l}\text { Disease } \\
\text { trajectory }\end{array}$ & $40(71 \%)$ & $51(88 \%)$ & 0.05 \\
\hline $\begin{array}{l}\text { Diagnosis of advanced cancer with progressive } \\
\text { disease despite second-line systemic therapy } \\
\text { (incurable) }\end{array}$ & $\begin{array}{l}\text { Disease } \\
\text { trajectory }\end{array}$ & $39(70 \%)$ & $51(88 \%)$ & 0.06 \\
\hline
\end{tabular}

$\mathrm{N}=56$ in the second round; $\mathrm{N}=58$ in the third round. Because not all respondents answered all questions, in some instances the denominator used to calculate the percentages was different. *The McNemar test was used to examine the concordance in response between the second and third rounds.

Table 2: Major criteria for outpatient palliative care referral in third Delphi round

physician-hastened death is a highly controversial topic, ${ }^{21}$ palliative care was generally agreed to have an important role in exploration of these requests and discussion of alternative options to address suffering.

A major needs-based criterion was related to assistance with decision making or care planning, or both, which are key palliative-care domains. ${ }^{22,23}$ Timely introduction of palliative care can facilitate end-of-life discussions, enhance understanding of an illness, increase prognostic awareness, and improve end-of-life care outcomes. ${ }^{5,24-26}$ Because every patient with advanced disease could potentially benefit from assistance with decision making or care planning, this criterion is less specific than the symptom distress criteria. Further research is needed to determine the proportion of patients and oncologists who perceive that they need extra assistance related to palliative care and the specific decisions associated with this request, the optimal timing, and the patient-related and oncologist-related factors associated with a greater likelihood of requesting such services.

Three other major needs-based criteria involved patients with neurological complications of cancernamely, brain metastases, spinal cord compression, and delirium. These major sentinel events mark the beginning of progressive functional decline and are often associated with pronounced psychological concerns and caregiver distress. ${ }^{27,28}$ Furthermore, patients with these neurological complications often have shorter survival than those without neurological complications. Because of the anticipated care needs, these patients are highly suitable for outpatient palliative-care referral if they have not been referred already on the basis of other criteria.

The ideal time for patients to be referred to outpatient palliative care has been debated. Our panellists identified two major time-based criteria-within 3 months of advanced cancer diagnosis for patients with life expectancy of 1 year or less, and progressive disease despite two lines of palliative systemic (disease-modifying) therapy-as the most appropriate timing criteria for outpatient palliative-care referral. Both of these criteria involve patients with limited prognosis, which might represent the so-called Goldilocks zone. On the one hand, referrals that are too late might deprive patients of the full benefits associated with longitudinal palliative care, such as timely symptom management to minimise crises and end-of-life discussions to attenuate the aggressiveness of end-of-life care. On the other hand, referrals that are too early might result in patients being seen by palliative-care specialists when they have few concerns and thus might not derive as much benefit. Furthermore, a large volume of early consultations could potentially overwhelm the limited infrastructure of palliative-care programmes. Neither performance status nor prognosis were included as major criteria, perhaps because of the variability in their determination. ${ }^{29,30}$

The panellists also identified 36 minor criteria, which might be used to support referral in aggregate, but might not individually be adequate to trigger a referral in the absence of other factors. One question is whether a referral score should be created, with different weights assigned for each criterion on the basis of its relative importance (eg, 2 points for a major criterion, 1 point for a minor criterion). The advantage of a score is that such a system would allow prioritisation and customisation of the referral process within each institution (eg, higher threshold for resource-limited settings), and ultimately standardisation of the referral process. However, referral scores might be cumbersome to apply, ${ }^{31}$ and further research is needed to derive and validate them.

Our list of consensus criteria represents a key step towards standardisation of the referral process, which is presently haphazard. Importantly, these criteria should serve as guiding principles, and should augment rather than replace clinical judgment. An oncologist might decide to refer a patient to palliative care at any time, even if this patient does not meet any of the criteria. Future research should assess the proportion of patients who meet each of these criteria in the oncology setting, the feasibility of applying these criteria in clinical practice, and the barriers to implementation as perceived by patients, families, and oncologists in different settings. Furthermore, these criteria will need to be customised for each institution on the basis of resource availability and local health-care culture. More studies are also needed to examine the validity of these criteria to determine whether application improves 


\section{Search strategy and selection criteria}

We searched MEDLINE and Embase with the search terms "neoplasms", "palliative care" or "supportive care", and "outpatient " or "ambulatory" or "clinic" for articles published in English between Jan 1, 1948, and Sept 9, 2015, the date of our final search. We also searched our files for relevant papers. The final list was generated on the basis of originality and relevance to the scope of this study.

patient outcomes and is cost-effective..$^{5}$ Previous studies have consistently shown that oncologists' attitudes towards palliative care vary widely, which can act as a barrier to referral..$^{32,33}$ Whether standardised referral criteria can help to reduce this variability would be useful to establish.

Our study has several limitations. First, the Delphi survey was based on the input of highly selected experts by design, which could incur bias. For example, dually trained palliative oncologists comprised more than half the panel, and might have a higher or lower threshold for referral than the typical oncologist. Importantly, we specifically invited individuals who were active clinically, had outpatient palliative-care clinics in their institution, and had relevant expertise to address the research question because of their academic or administrative experience. Thus, these experts have a good understanding not only of the topic, but also of the realities of clinical practice, such as the level of primary palliative care delivered by oncologists locally and how specialty palliative care can complement their practice. Before the proposed referral criteria can be adopted in routine practice, however, further studies are needed to examine them from the perspectives of key stakeholders, including general oncologists, palliative-care specialists, patients and their families. Second, most experts are from highincome nations because palliative care and outpatient clinics are more established. Third, we asked experts to focus on developing an ideal set of criteria at secondary or tertiary care hospitals with an interdisciplinary palliative-care team in place, assuming that service delivery is not an issue. Given that resources are often limited in reality, these criteria would need to be further customised before application at the institution level. Finally, we focused on specialty palliative-care referral only; the amount of primary palliative care that oncologists should be delivering is beyond the scope of this study, and is being actively investigated by other groups. ${ }^{34}$

Our international panel reached consensus on 11 major and 36 minor criteria for outpatient palliative-care referral for patients with advanced cancer being treated at secondary or tertiary care hospitals. These criteria should be further tailored to each institution, and could help streamline and standardise clinical practice, research, and resources related to palliative-care access for patients with cancer.

\section{Contributors}

DH and EB analysed and interpreted the study data. All authors contributed to data collection, reviewed the report, and approved the final version.

\section{Declaration of interests}

We declare no competing interests.

\section{Acknowledgments}

This study is partly supported by a grant from the Multinational Association of Supportive Care in Cancer. DH and EB are supported partly by an American Cancer Society Mentored Research Scholar Grant in Applied and Clinical Research (MRSG-14-1418-01-CCE) and a US National Institutes of Health grant (R21CA186000-01A1). PG was supported partly by a National Institutes of Health grant (1R01CA190101-01).

\section{References}

1 Temel JS, Greer JA, Muzikansky A, et al. Early palliative care for patients with metastatic non-small-cell lung cancer. $N$ Engl J Med 2010; 363: 733-42.

2 Zimmermann C, Swami N, Krzyzanowska M, et al. Early palliative care for patients with advanced cancer: a cluster-randomised controlled trial. Lancet 2014; 383: 1721-30.

3 Bakitas M, Lyons KD, Hegel MT, et al. Effects of a palliative care intervention on clinical outcomes in patients with advanced cancer: the Project ENABLE II randomized controlled trial. JAMA 2009; 302: 741-49.

4 Yennurajalingam S, Urbauer DL, Casper KL, et al. Impact of a palliative care consultation team on cancer-related symptoms in advanced cancer patients referred to an outpatient supportive care clinic. J Pain Symptom Manage 2010; 41: 49-56.

5 Hui D, Kim SH, Roquemore J, Dev R, Chisholm G, Bruera E. Impact of timing and setting of palliative care referral on quality of end-of-life care in cancer patients. Cancer 2014; 120: 1743-49.

6 Cherny NI, Catane R. Palliative medicine and the medical oncologist. Defining the purview of care. Hematol Oncol Clin North Am 1996; 10: 1-20.

7 Abrahm JL. Integrating palliative care into comprehensive cancer care. JNCCN 2012; 10: 1192-98.

8 Hui D, Elsayem A, De la Cruz M, et al. Availability and integration of palliative care at US cancer centers. JAMA 2010; 303: 1054-61.

9 Hui D, Bruera E. Models of integration of oncology and palliative care. Ann Palliat Med 2015; 4: 89-98.

10 Follwell M, Burman D, Le LW, et al. Phase II study of an outpatient palliative care intervention in patients with metastatic cancer. J Clin Oncol 2009; 27: 206-13.

11 Temel JS, Jackson VA, Billings JA, et al. Phase II study: Integrated palliative care in newly diagnosed advanced non-small-cell lung cancer patients. J Clin Oncol 2007; 25: 2377-82.

12 Hui D, Bansal S, Strasser F, et al. Indicators of integration of oncology and palliative care programs: an international consensus. Ann Oncol 2015; 26: 1953-59.

13 Levy MH, Smith T, Alvarez-Perez A, et al. NCCN clinical practice guidelines in oncology. http://www.nccn.org/professionals/ physician_gls/pdf/palliative.pdf (accessed Dec 29, 2015).

14 Smith TJ, Temin S, Alesi ER, et al. American Society of Clinical Oncology provisional clinical opinion: the integration of palliative care into standard oncology care. J Clin Oncol 2012; 30: 880-87.

15 Pizzo PA, Walker DM, Bomba PA, et al. Dying in America: Improving quality and honoring individual preferences near the end of life. Washington, DC: Insitute of Medicine, 2015

16 Hui D, Meng YC, Bruera S, et al. Referral criteria for outpatient palliative cancer care: a systematic review. Oncologist 2016; 21: 895-901.

17 Smith AK, Thai JN, Bakitas MA, et al. The diverse landscape of palliative care clinics. J Palliat Med 2013; 16: 661-68.

18 Weissman DE, Meier DE. Identifying patients in need of a palliative care assessment in the hospital setting: a consensus report from the Center to Advance Palliative Care. J Palliat Med 2011; 14: 17-23.

19 Higginson IJ, Finlay I, Goodwin DM, et al. Do hospital-based palliative teams improve care for patients or families at the end of life? J Pain Symptom Manage 2002; 23: 96-106. 
20 Hearn J, Higginson IJ. Do specialist palliative care teams improve outcomes for cancer patients? A systematic literature review. Palliat Med 1998; 12: 317-32.

21 Emanuel EJ, Onwuteaka-Philipsen BD, Urwin JW, Cohen J. Attitudes and practices of euthanasia and physician-assisted suicide in the United States, Canada, and Europe. JAMA 2016; 316: 79-90.

22 Bernacki RE, Block SD. Communication about serious illness care goals: a review and synthesis of best practices. JAMA Intern Med 2014; 174: 1994-2003.

23 Brighton LJ, Bristowe K. Communication in palliative care: talking about the end of life, before the end of life. Postgrad Med J 2016; 92: 466-70.

24 Wright AA, Zhang B, Ray A, et al. Associations between end-of-life discussions, patient mental health, medical care near death, and caregiver bereavement adjustment. JAMA 2008; 300: 1665-73.

25 Temel JS, Greer JA, Admane S, et al. Longitudinal perceptions of prognosis and goals of therapy in patients with metastatic nonsmall-cell lung cancer: results of a randomized study of early palliative care. J Clin Oncol 2011; 10: 2319-26.

26 Enzinger AC, Zhang B, Schrag D, Prigerson HG. Outcomes of prognostic disclosure: associations with prognostic understanding, distress, and relationship with physician among patients with advanced cancer. J Clin Oncol 2015; 33: 3809-16.

27 Breitbart W, Gibson C, Tremblay A. The delirium experience: delirium recall and delirium-related distress in hospitalized patients with cancer, their spouses/caregivers, and their nurses.

Psychosomatics 2002; 43: 183-94.
28 Bruera E, Bush SH, Willey J, et al. Impact of delirium and recall on the level of distress in patients with advanced cancer and their family caregivers. Cancer 2009; 115: 2004-12.

29 Kim YJ, Hui D, Zhang Y, et al. Differences in performance status assessment among palliative care specialists, nurses, and medical oncologists. J Pain Symptom Manage 2015; 49: 1050-58.

30 Hui D, Kilgore K, Nguyen L, et al. The accuracy of probabilistic versus temporal clinician prediction of survival for patients with advanced cancer: a preliminary report. Oncologist 2011; 16: 1642-48.

31 Glare PA, Semple D, Stabler SM, Saltz LB. Palliative care in the outpatient oncology setting: evaluation of a practical set of referral criteria. J Oncol Pract 2011; 7: 366-70.

32 Schenker Y, Crowley-Matoka M, Dohan D, et al. Oncologist factors that influence referrals to subspecialty palliative care clinics. J Oncology Prac 2013; 10: e37-44.

33 Hui D, Park M, Liu D, Reddy A, Dalal S, Bruera E. Attitudes and beliefs toward supportive and palliative care referral among hematologic and solid tumor oncology specialists. Oncologist 2015; 20: $1326-32$.

34 Bickel KE, McNiff K, Buss MK, et al. Defining high-quality palliative care in oncology practice: an American Society of Clinical Oncology/American Academy of Hospice and Palliative Medicine guidance statement. J Oncol Pract 2016; 12: e828-38. 